\title{
Moluscos bivalves: Organismos Bioindicadores da Qualidade Microbiológica das Águas: Uma Revisão ${ }^{1}$
}

\author{
Bivalve molluscs: Microbiological Quality Bioindicators Bodies of Water: A Review ${ }^{1}$ \\ Norma Suely Evangelista-Barreto ${ }^{2}$, Oscarina Viana de Sousa ${ }^{3}$, Regine Helena Silva dos \\ Fernandes Vieira $* 4$ \\ ${ }^{23}$ LABOMAR - UFC Fortaleza, CE., Cx. Postal 12.168, CEP 60355-970. \\ ${ }^{4}$ Professora do DEP/CCA/UFC Fortaleza, CE, Cx. Postal 12.168, CEP 60356-000.
}

Resumo: A exploração sustentada dos recursos marinhos é um desafio para todos aqueles que se preocupam com a qualidade de vida do ser humano. $\mathrm{O}$ cultivo de animais marinhos, como moluscos bivalves (ostras e mexilhões) além de ser uma fonte alternativa de alimentos, é uma opção para a subsistência das populações costeiras, à medida que esse produto ganha espaço no mercado, como por exemplo, as regiões sul e sudeste. No entanto, a descarga de esgotos em reservatórios d'água, como os rios e o mar, são as causas poluidoras mais comuns dos ambientes aquáticos, comprometendo a qualidade dos produtos pesqueiros. As ostras são organismos filtradores, capazes de ingerir partículas em suspensão, as quais podem carrear elevadas concentrações de microrganismos patogênicos. Por outro lado, o hábito de ingerir este alimento in natura, sem nenhum tratamento prévio, pode causar toxinfecções alimentares em humanos, principalmente em indivíduos imunocomprometidos. Assim, faz-se necessário a adoção de medidas preventivas para o controle da veiculação de agentes patogênicos, como a seleção de área de captura desses organismos, depuração após captura, controle da água e algas usadas como alimento, seguido de depuração, bem como a manipulação e armazenamento adequado desses alimentos.

Palavras-chave: Ostras, poluição, saúde pública

Abstract: The sustainable exploration of marine resources is a challenge to everybody worried with the quality of human life. The cultivation of marine organisms like bivalve mollusks (oysters and clams) is an alternative food source and also an option to the survival of coastal communities while the consumption of grown up in market like happens food in south and southeast regions of Brazil. However, the domestic sewer discharges into water reservoir like rivers and ocean are the pollution source more frequent on aquatic environments endanger the fish product quality. Oysters are filter organisms able to ingest suspension particles including high concentrations of pathogenic microorganisms. On the other hand, the frequent custom of eat this food in natura, without cooking can cause foodborne toxinfection mainly in immune compromised individuals. So, it is 
necessary to adopt preventive steps to control of pathogenic agents circulation as the selection of mollusks catch areas, depuration after catch, control of water and algae that are food for oysters and the adequate handling and store of this food.

Key words: Oysters, pollution, public health.

*Autor correspondente - E.mail- regine@ labomar.ufc.br
Recebido em 20.04.2008. Aceito em 27.06.2008

\section{Introdução}

A descarga de esgotos em reservatórios, rios e/ou mar, são as causas poluidoras mais comuns de ambientes aquáticos registradas no mundo inteiro (CONSTANTINIDO, 1994). Tal contaminação origina dois relevantes problemas em saúde pública: riscos associados a banhos em locais contaminados e o consumo de organismos aquáticos, como por exemplo, as ostras e os mexilhões.

As ostras oferecem um grande risco ao consumidor, porque dentre os animais marinhos capturados em ambientes contaminados por microrganismos, os moluscos bivalves são os que oferecem maiores riscos à Saúde Pública, por serem organismos filtradores e bioacumuladores. Por esta razão, as ostras e os mexilhões, são utilizados mundialmente como indicadores de poluição fecal (HENRIQUES et al., 2000).

A ostra é um molusco pertencente à classe Bivalvia com grande capacidade de converter a produção primária do mar em proteína animal devido à filtração de uma vasta quantidade de água através de seu mecanismo de alimentação. Inicialmente, as ostras eram usadas como um importante produto, apenas, para a subsistência das famílias próximas as áreas de mangue. Atualmente, o cultivo de ostra tem se destacado como uma alternativa de emprego e renda, à medida que o produto ganha espaço no mercado, a exemplo do que vem acontecendo nas regiões sul e sudeste.

Devido ao hábito das pessoas em consumir ostras cruas e, ainda vivas, é compreensível a descrição constante de surtos de enfermidades transmitidas por esse alimento. Segundo COOK et al. (2001), a maior epidemia associada ao consumo de moluscos ocorreu em 1988 em Shangai, China, tendo sido relatados mais de 300.000 casos de hepatite A. A epidemia foi causada pelo consumo de moluscos crus capturados em um porto que recebia despejos de esgotos domésticos sem tratamento. 
Por isso, nos diversos países em que as ostras são comercializadas, foi desenvolvido um conjunto de normas próprias para o processo de comercialização dos moluscos devido ao risco inerente ao seu consumo. Estas normas são baseadas em análises microbiológicas na água do cultivo e/ou tecido e líquido intervalvar (MACHADO et al., 2001). No Brasil, a legislação pertinente, que estabelece critérios e normas de qualidade, com o objetivo de proteger e preservar sanitariamente as águas destinadas ao consumo e residuais, é bastante extensa e complexa (MORELLI, 2003).

Por outro lado, o consumo desses animais em nosso meio, sem cocção prévia, pode ser responsável pela veiculação de doenças como a hepatite, febre tifóide, cólera, salmonelose e envenenamento por biotoxinas paralisantes que podem levar o consumidor à morte. A capacidade filtrante das ostras é de cinco litros de água/hora o que acarreta a retenção, no manto, de $75 \%$ das espécies bacterianas presentes no seu ambiente (SANCHEZ et al., 1991; BARROS et al., 2005). Dessa maneira, para tentar solucionar essa questão, ou pelo menos minimizar possíveis riscos à saúde pública, algumas áreas de cultivo têm tido seu produtos submetidos a programas de monitoramentos regulares (GARCIA, 2005).

\section{Moluscos Bivalves}

Moluscos bivalves, como os mexilhões, ostras e vieiras são organismos filtradores que se alimentam principalmente de microalgas presentes na água do mar, concentrando em seus tecidos, grande quantidade de substâncias químicas, resíduos orgânicos e inorgânicos, e microrganismos presentes na água (DAME, 1996). Os agentes que podem ser veiculados são de natureza biológica (bactérias, vírus, parasitas e toxinas de moluscos) e química (metais pesados, resíduos de pesticidas e, mais raramente, antibióticos, quando se trata de cultivo/criação) (MORAES, 2000). Assim, a concentração desses elementos presentes na água e nos tecidos desses organismos, reflete as condições ambientais em que vivem, podendo seu consumo trazer sérios danos ao organismo humano, representando um risco à saúde pública, uma vez que alguns moluscos chegam a filtrar até 100 litros de água por dia (DAME, 1996).

A ostra do mangue, Crassostrea rhizophorae, apresenta uma produção mundial pequena. No entanto, esta afirmação pode ser subestimada uma vez que, são raros os levantamentos estatísticos de produção na maioria dos países latino- 
americanos onde a espécie ocorre. A produção mundial de moluscos bivalves cultivados em 2004 foi de 13,2 milhões de toneladas, tendo as ostras, participado com 4,6 milhões/ton., o que corresponde a $31 \%$ da produção total desses organismos (FAO, 2006). No Brasil, o principal produtor nacional é o Estado de Santa Catarina, participando em 2005, com 14.175,7 mil toneladas entre ostras e mexilhões, apesar da produção de ostras ter sofrido uma queda de quase $23 \%$. Florianópolis se destaca por apresentar desse total uma produção de $54 \%$, ou seja, 1.056,38 toneladas/ano (PANORAMA DA AQÜICULTURA, 2006).

A ostra Crassostrea rhizophorae, apresenta uma distribuição geográfica que abrange a região Sul do Caribe, Venezuela, Suriname e Brasil até o Uruguai (RIOS, 1994), sendo uma das principais espécies de bivalves consumidas no nordeste brasileiro. No Estado do Ceará, tem-se por hábito o consumo desse molusco na forma in natura, o que aumenta o risco de intoxinfecções para a população.

O extrativismo de ostras no litoral cearense é feito por comunidades tradicionais como parte de sua estratégia de subsistência e segurança alimentar, uma vez que o consumo de ostras faz parte do hábito dessas comunidades. Por outro lado, a coleta das ostras nem sempre é feita de forma a preservar o ecossistema manguezal, sendo extraídas por meio de corte nas raízes dos mangues onde se fixam e crescem em abundância. A forma de exploração realizada pelos nativos é insustentável tanto para as ostras quanto para o ecossistema (GOMES, 2006).

Segundo GARCIA (2005) para garantir a qualidade do produto deve-se observar a qualidade ambiental, visto que uma das principais fontes de contaminação se deve à degradação do ambiente, muitas vezes decorrente do deságüe de efluentes domésticos, industriais e agrícolas, que podem causar enfermidades e prejudicar o crescimento das espécies. Um dos efeitos mais graves do escoamento superficial urbano é sua interceptação no habitat aquático (PITT, 1995), que pode comprometer a qualidade sanitária das águas em uma determinada região. $\mathrm{Na}$ tentativa de minimizar os problemas relacionados à qualidade sanitária das águas de cultivo e dos produtos provenientes da aqüicultura, diversos países estabeleceram limites máximos permissíveis da contaminação fecal para áreas de extração e cultivo. No Brasil, o Conselho Nacional do Meio Ambiente (CONAMA) e o Ministério da Saúde estabeleceram condições e limites para que estas atividades possam ser praticadas. 


\section{Legislação}

De acordo com a Legislação CONAMA n ${ }^{\circ}$ 357, de 17 de maio de 2005, as águas salobras destinadas à proteção das comunidades aquáticas, à aqüicultura e à atividade de pesca estão inseridas na Classe 1. Nesta classe, especificamente, para o cultivo de moluscos bivalves destinados à alimentação humana, a média geométrica de coliformes termotolerantes (CT), de um mínimo de 15 amostras coletadas, no mesmo local, não deverá exceder 43 por 100 mililitros, e o percentual de $90 \%$ não deverá ultrapassar 88 coliformes termotolerantes por 100 mililitros.

Para MACHADO et al. (2001) a determinação de coliformes fecais em tecidos moles e líquido intervalvar, para avaliar a qualidade dos moluscos, produzidos com fins comerciais, apresenta maiores possibilidades como padrão de normatização no cultivo do que a análise de água das áreas destinadas.

De acordo com a Resolução ${ }^{\circ} 12$, de 02 de janeiro de 2001, da Agência Nacional de Vigilância Sanitária ANVISA (BRASIL, 2001) não é estabelecido limites para o grupo dos CT, nem critérios para a avaliação de moluscos consumidos in natura, apresentando apenas, uma tolerância indicativa de moluscos bivalves, como carne de siri e similares cozidos, temperados e não, industrializados resfriados ou congelados de $5 \times 10$ coliformes quando estocados a $45^{\circ} \mathrm{C} / \mathrm{g}$ (artigo 7, alínea b). Anteriormente, a Portaria n451 (BRASIL, 1997) especificava limites de NMP para CT de $10^{2} / \mathrm{g}$ para pescados consumidos crus (item IV, alínea a) e sendo as ostras, moluscos que geralmente são consumidos crus, torna-se incompreensível a revogação desta, uma vez que a Resolução $n^{\circ} 12$ da ANVISA dificulta a avaliação da qualidade microbiológica do alimento em questão.

Assim, como a Legislação Brasileira não é satisfatória para que se obtenha uma efetiva avaliação microbiológica desses organismos, tem-se buscado padrões internacionais, como o EUSQAP (The European Union Shellfish Quality Assurance Programme), este programa classifica os moluscos bivalves em três classes: A, B e C. Para cada classe é permitido uma quantidade de coliformes termotolerantes por $100 \mathrm{~g}$ de massa visceral e líquido intervalvar. Para a classe A, a tolerância é de < 300 CT/100 g, na classe B, 90\% das amostras não podem exceder $6.000 \mathrm{CT} / 100 \mathrm{~g}$ e na classe $\mathrm{C}$, não podem exceder a $60.000 \mathrm{CT} / 100 \mathrm{~g}$.

\section{Consumo $x$ Riscos}

O processo de intervenção e controle dos agravos à saúde do consumidor tem despertado interesse e se revelado efetivo 
na diminuição de certos riscos microbianos, como a presença de Salmonella spp, Shigella spp., Escherichia coli O157:H7 e Vibrio cholerae toxigênico, dentre outros (VARNAM \& EVANS, 1991).

No nordeste, particularmente a Praia do Futuro (Ceará-CE), é uma das áreas de maior consumo destes bivalves. Entretanto, sob o ponto de vista microbiológico, a qualidade do marisco é duvidosa e a comercialização é realizada em barracas cujo controle sanitário mostra-se precário, apontando a necessidade de investigação sob o ponto de vista sanitário (BARROS et al., 2005). MORELLI et al. (2003) estudando dois estabelecimentos nessa praia, observaram que $40 \%$ das amostras apresentavam valores de CT acima de $10^{2} / \mathrm{g}$, enquanto Barros et al. (2005) encontraram valores superiores em $70 \%$ das ostras comercializadas na mesma área e assim fora dos padrões estabelecidos pela legislação vigente (Portaria $\left.n^{0} 451\right)$.

A elevada ocorrência de Escherichia coli é particularmente reportada em infecções gastrentéricas, tanto em indivíduos imunocomprometidos, como naqueles sadios. Dessa forma, a presença desse microrganismo é reconhecida como um indicador de outros patógenos, tanto de natureza bacteriana quanto viral ou parasitária, cujos prejuízos à população são amplamente reconhecidos (BRASIL, 2001).

SILVA et al. (2003) usando CT e Salmonella como indicadores de contaminação fecal em amostras de ostras, Crassostrea rhizophorae, coletadas no estuário do rio Cocó, Fortaleza - CE, relataram que $30 \%$ das amostras apresentavam valores para CT acima de $10^{2} / \mathrm{g}$ e Salmonella presente em $57 \%$ das amostras. A Legislação impõe ausência total para Salmonella em qualquer amostra aleatória de 25 g (BRASIL, 2001). Nos Estados Unidos da América, as salmonelas não tifóides têm sido associadas ao consumo de peixes e crustáceos, Salmonella Paratyphi e $S$. Enteridis a camarões e moluscos bivalves e $S$. Typhi o principal agente associado com doenças veiculadas por moluscos (FELDHUSEN, 2000).

A presença de enterococos em amostras de moluscos sugere um alto grau de contaminação na água de cultivo por esgotos. No entanto, na legislação não há limites para esse gênero em amostras de ostras. Segundo MORELLI et al. (2003) a presença de Enterococcus faecalis foi observada em $70 \%$ das ostras comercializadas em dois estabelecimentos na Praia do Futuro, enquanto SILVA et al. (2004) confirmaram o mesmo 
microrganismo em $68 \%$ dos isolados de ostras, coletadas no estuário do Rio Cocó.

O grupo dos coliformes quando comparado aos enterococos são mais fáceis de serem isolados e identificados, além de estarem mais relacionados a infecções intestinais, embora os enterococos sejam mais resistentes às condições ambientais adversas, ao congelamento e sobreviva maior tempo em alimentos congelados (JAY, 1991).

Outro grupo importante relacionado a surtos alimentares são os víbrios. Estes microrganismos fazem parte da microbiota natural de ambientes marinhos e estuarinos. A quantificação de Vibrio e coliformes em amostras de água e ostras Crassostrea rhizophorae, coletadas no estuário do Rio Jaguaribe, município de Fortim - CE, foi maior nas amostras de ostras do que na água, confirmando o potencial bioacumulador destes organismos (VIEIRA et al., 2007). A água é o ambiente natural de $V$. parahaemolyticus e por este microrganismo está associado a diversos surtos alimentares, sua presença traz diversos riscos aos consumidores. Pereira et al. (2004) analisando amostras de ostras provenientes de 15 restaurantes no Rio de Janeiro, revelaram a elevada incidência de V. parahaemolyticus (86\%) nas ostras comercializadas nesses estabelecimentos.
SOUSA et al. (2004) isolaram Vibrio parahaemolyticus e $V$. cholerae, em 12 amostras de ostras, coletadas no estuário do Rio Cocó, Ceará, observando a presença de $V$. cholerae não 01 e não 0139 e V. parahaemolyticus em 33 e $8 \%$ das amostras, respectivamente. Diferentes organismos aquáticos, como os mariscos, zooplâncton, ostras etc., têm sido considerados como habitats potenciais de $V$. cholerae $\mathrm{O} 1$ no meio aquático, onde esta interação parece estar associada à capacidade desses víbrios produzirem quitinase e usarem a quitina da carapaça desses organismos como fonte de nutrientes (GASPARI et al., 2006).

Outro microrganismo relevante é o gênero Aeromonas que de um modo geral são os contaminantes mais comuns encontrados em peixes e produtos marinhos, uma vez que este gênero é primariamente autóctone de ambientes aquáticos (HÃNNINEN et al., 1997). Nos rios, elas fazem parte da microbiota normal podendo até se multiplicar em condições ambientais adequadas (MORES, 1994). A presença de Aeromonas spp. foi observada em $67 \%$ das amostras de ostras estudadas por Evangelista-Barreto et al. (2006).

Com relação à presença dos vírus, BARARDI et al. (2001) citam que a ocorrência desses microrganismos em áreas de cultivo como o vírus da hepatite $\mathrm{A}$ 
(eliminado nas fezes de pessoas infectadas) e os causadores de diarréias severas (rotavírus, astrovírus, vírus Norwalk dentre outros) podem ser encontrados tanto em águas liberadas para o consumo humano quanto em moluscos. Mais resistentes ao tratamento de esgotos, esses microrganismos sobrevivem mais tempo do que as bactérias em ambientes naturais, tendo outro padrão a distribuição nas diversas épocas do ano. VIEIRA (1999) relatou o isolamento do vírus Small Round Structured Viruses - SRSV causador de gastroenterite, e naturalmente presente em ostras contaminadas.

Outro fato importante para as autoridades sanitárias se refere à resistência antimicrobiana bacteriana que tem aumentado nos últimos anos em virtude da prescrição excessiva de antibióticos por parte de médicos, o uso indiscriminado pelo público e o emprego dessas drogas nos cultivos intensivos de animais (HARAKEH et al., 2006). O uso de antibióticos nas rações, visando efeito profilático no tratamento de infecções animais como promotor de crescimento tem contribuído para a perpetuação de estirpes resistentes e patogênicas (PINTO, 2000).

A análise de ostras de cultivo provenientes do estuário do Rio Pacoti, apresentou um alto percentual de resistência aos antimicrobianos imipenem (80\%) e ampicilina (48\%) (ATAYDE, 2007). Por outro lado, cepas de E. coli isoladas do músculo de ostras comercializadas em barracas de praia apresentaram um padrão de resistência múltipla a diferentes antimicrobianos, com resistência de $70 \%$ a ampicilina (MORELLI et al., 2003). Setenta e quatro por cento dos isolados de Aeromonas, apresentaram resistência antimicrobiana a pelo menos um de oito antimicrobianos testados. Nesse estudo, as espécies Aeromonas sp., A. caviae e A. media, apresentaram susceptibilidade a tetraciclina em $40, \quad 81$ e $88 \%$, respectivamente

(EVANGELISTABARRETO et al., 2006). Segundo Hedges et al. (1985) a resistência em cepas de Aeromonas spp. à tetraciclina pode estar relacionada com a presença de plasmídios.

\section{Medidas de Controle}

Programas de monitoramentos da qualidade da água incluem uma série de estudos que, em conjunto, permitem avaliar o cenário ambiental de um determinado corpo d'água, possibilitando o estabelecimento do diagnóstico do recurso hídrico e servindo de parâmetro para seu uso, como a balneabilidade. Em se tratando de maricultura, um dos estudos de grande importância num monitoramento é a qualidade sanitária das águas (GARCIA, 
2005), minimizando ou até mesmo evitando que o ambiente de cultivo se transforme numa fonte desses agentes (BARARDI et al., 2001).

A colimetria de águas, provenientes das áreas onde são coletados bivalves destinados ao consumo humano, constituise sempre em subsídio científico para as autoridades sanitárias envolvidas na fiscalização e no controle da qualidade do alimento (WOOD, 1996). Em termos de saúde pública, considerando as doenças e surtos de doenças relacionadas com o consumo desse alimento, é importante e necessária a adoção de medidas preventivas para o controle de veiculação de agentes. Essas medidas incluem: a seleção de área de captura desses organismos (área selecionada de águas livres de contaminação); a depuração após captura; o controle de água e algas que as ostras usam como alimento, seguida de depuração (MORAES, 2000).

Falhas no transporte, manutenção e no manuseio não podem ser esquecidas, pois representam pontos fundamentais e de forte influência na manutenção e qualidade dos pescados (BARROS et al., 2005).

\section{Referências Bilbiograficas}

ATAYDE, M.A. Bacteriologia da ostra Crassostrea rhizophorae e da água do entrono no estuário do Rio Pacoti (Eusébio-Ceará) - Identificação de
Escherichia coli e sua susceptibilidade a diferentes antimicrobianos. 2007. 35p. Monografia (Engenharia de Pesca) Centro de Ciências Agrárias, Universidade Federal do Ceará, CE, 2007.

BARARDI, C.R.M.; SANTOS, C.S.; SIMÕES, C.M.O. Ostras de qualidade em Santa Catarina. Ciência Hoje, Rio de Janeiro, v.29, n.172, p.70-73, 2001.

BARROS, L.M.O.; THEOPHILO, G.N.D.; COSTA, R.G.; RODRIGUES, D.P.; VIEIRA, R.H.S.F. Contaminante fecal da ostra Crasssotrea rhizophorae comercializada na Praia do Futuro, Fortaleza-Ceará. Revista Ciências Agronômica, Fortaleza, v.36, n.3, p.285289, 2005.

BARROS, L.M.O.; SOUSA, O.V.; LIMA, E.A.; MACRAE, A.; VIEIRA, G.H.F.; VIEIRA, R.H.S.F. Víbrios sacarose negativos isolados de ostras Crassostrea rhizophorae comercializadas em barracas de praia na cidade de Fortaleza, Ceará, Brasil. Boletim Técnico-Científico do CEPNOR, v.7, p. 9-16, 2007.

BRASIL. Agência Nacional de Vigilância sanitária. Resolução RDC $\mathrm{N}^{\circ} 12$, de 2 de janeiro de 2001. Regulamento técnico sobre os padrões microbiológicos para alimentos. Diário Oficial [da] República 
Federativa do Brasil. Poder Executivo, Brasília, DF. 10 jan. 2001. Seção 1.

BRASIL. Ministério da Saúde. Portaria MS N451, de 19 de setembro de 1997. Aprova o regulamento técnico princípios gerais para estabelecimento de critérios e padrões microbiológicos para alimentos. Diário Oficial [da] República Federativa do Brasil. Brasília, DF. 27 set. 1997.

CONSELHO NACIONAL DO MEIO AMBIENTE - CONAMA. Resolução N³57 de 17 de março de 2005. Dispõe sobre a qualidade dos corpos de água $\mathrm{e}$ diretrizes ambientais para o seu enquadramento, bem como estabelece as condições e padrões de lançamentos de efluentes e dá outras providências. D.O.U., Brasília, DF. Disponível em <http://www.mma.gov.br/conama/res/res0 5/res35705.pdf $>$ Acesso em: 06 de jan. de 2007.

CONSTANTINIDO, G.A saúde do pescado depende diretamente da saúde do ambiente. Revista Higiene Alimentar, São Paulo, v.8, n.32, p.5-6, 1994.

COOK, D.W.; BURKHARDT III. W.; DePAOLA, A.; McCARTHY, S.A.; CALCI, K. R. Molluscan shellfish: oyster, mussels and clams. In: Downes, F.P., ITO, K. (Ed.) Compedium of methods for the microbiological examination of foods. $4^{\mathrm{a}}$ ed. APHA: Washington, 2001. p.507-514.

DAME, R.F. Organismic level processes. In: Ecology of marine bivalves: an ecosystem approach. New York: CRC Press. Cap. 3, 1996. p.35-74.

EVANGELISTA-BARRETO, N.S.; VIEIRA, R.H.S.F.; CARVALHO, F.C.T.; TORRES, R.C.O.; SANT'ANNA, E.S. Aeromonas spp. isolated from oysters (Crasssotrea rhizophorae) from a natural oyster bed, Ceará, Brazil. Revista do Instituto de Medicina Tropical, São Paulo, v.48, n.3, p.129-133, 2006.

FAO. The state of world fisheries and aquaculture, 2006. Electronic Publishing Policy and Support Branch, Roma, 2007. Disponível em: < ftp://ftp.fao.org/docrep/fao/009/a0699e/a06 9

9e.pdf>. Acesso em: 16 ago. 2007.

FELDHUSEN, F. The role of seaffod in bacteria foodborne diseases. Microbes and Infection, Paris, v.2, p.1651-1660, 2000.

GARCIA, A.N. Contaminação microbiológica na área de cultivo de moluscos bivalves de Anchieta (Espírito Santo, Brasil). 2005. 66p. Monografia (Curso de Graduação em Oceanografia) Centro de Ciências Humanas e Naturais, 
Universidade Federal do Espírito Santo, ES, 2005.

GASPARI, E.N.; BOZZOLI, L.M.; RISTORI， C.A.; ROWLANDS， E.G.; IRINO, K.; TORRES, D. D.; TAMPLIN, M. Aplicação de Anticorpos Monoclonais na Detecção de Enteropatógenos em Amostras de Origem Clínica, Alimentar e Ambiental para a Produção de Kits para Imunodiagnóstico.

Boletim

Epidemiológico Paulista, São Paulo, v.3, n.35, 2006.

GOMES, R.S. Diagnóstico socioeconômico das marisqueiras da mangabeira que participam do projeto de ostreicultura comunitário da Fundação Alphaville, Eusébio - Ceará. 2006. 52p. Monografia (Engenharia de Pesca) - Centro de Ciências Agrárias, Universidade Federal do Ceará, CE, 2006.

HÃNNINEN, M.-L; OIVANEN, P.; HIRVELÄ-KOSKI, V. Aeromonas species in fish, fish-eggs, shrimp and freshwater. International Journal of Food Microbiology, Amsterdam, v.34, p.17-26, 1997.

HARAKEH, S.; YASSINE, H.; ELFADEL, M. Antimicrobial-resistant patterns of Escherichia coli and Salmonella strains in the aquatic Lebanese environments. Environmental Pollution, Barking, v.143, p.269-277, 2006.

HEDGES, R.W.; SMITH, O.; BRAZIL, G. Resistence plasmids of aeromonads. Journal of General Microbiology, London, v.13, p.2191-2195, 1985.

HENRIQUES, M.B.; ZAMARIOLI, L.A.; PEREIRA, O.M.; FAUSTINO, J.S. Contaminação bacteriológica no tecido mole do mexilhão Perna perna (LINAEUS, 1758) nos bancos naturais do litoral da Baixada Santista, Estado de São Paulo. Arquivo de Ciências do Mar, Fortaleza, v.33, p.69-79, 2000.

JAY, J.M. Indicators of food microbial quality and safety. In: Modern Food Microbiology, $4^{\text {th }}$ ed., Nova York: Van Nostrand Reinhold, 1991. p.413-433.

MACHADO, I.C.; PAULA, A.M.R.; BUZZO, A.; JAKABI, M.; RISTORI, C.; SAKUMA, H. Estudo da ocorrência de contaminação orgânica no estuário de Cananéia, como subsídio para a extração, manejo e cultivo da ostra do mangue (Crasssotrea brasiliana). 2. Análise da ostra (tecidos moles e líquido intervalvar). Revista Higiene Alimentar, São Paulo, v.15, n.83, p.44-48, 2001.

MORAES, I.R.; DEL MASTRO, N.L.; JAKABI, M.; GELLI, D.S. Estudo da radiosensibilidade ao ${ }^{60} \mathrm{Co}$ do Vibrio 
cholerae $\mathrm{O} 1$ incorporado em ostras. Revista de Saúde Pública, São Paulo, v.34, n.1, p.39-32, 2000.

MORELLI, A.M.; VIEIRA, R.H.S.F.; REIS, C.M.F.; RODRIGUES, D.P.; FONTELES-FILHO, A.A. Indicadores de contaminação fecal para ostra-do-mangue (Crasssotrea rhizophorae) comercializada na Praia do Futuro, Fortaleza, Ceará. Revista Higiene Alimentar, São Paulo, v.17, p.81-88, 2003.

MORES, V.L. Bactérias do gênero Aeromonas em peixe Pintado (Pseudoplatystoma sp.) e pesquisa de alguns fatores de virulência a partir das cepas isoladas. 1994, 108p. Dissertação (Mestrado no Instituto de Ciências Biomédicas), Universidade de São Paulo, SP, 1994.

PANORAMA DA AQUICULTURA. Santa Catarina tem produção recorde de mexilhões em 2005. Panorama da Aqüicultura, Rio de Janeiro, v.16, n.94, p.30-31, 2006.

PEREIRA, C.S.; VIANA, C.M., RODRIGUES, D.P. Vibrio parahaemolyticus produtores de urease isolados a partir de ostras (Crassostrea rizophorae) coletadas in natura em restaurantes e mexilhões (Perna perna) de banco natural. Ciências e Tecnologia de
Alimentos, Campinas, v.24, n.4, p.591595, 2004.

PINTO, P.S.A. Aspectos sanitários da salmonelose como uma zoonose. Revista Higiene Alimentar, São Paulo, v. 14, n. 73, p. 39-43, 2000.

PITT, R.E. Effects of urban runoff on aquatic biota. In: Handbook of ecotoxicology. HOFFMAN, D.J.; RATTNER, B. A.; BURTON JÚNIOR, G. A.; CAIRNS JÚNIOR, J. (Eds). New York: Lewis Publishers, cap. 28, 1995. $755 \mathrm{p}$.

RIOS, E.C. Seashells of Brazil. Rio Grande: Fundação do Rio Grande - FURG, 1994. 368p.

SANCHEZ, P.S.; STOPPE, N.C.; ZANOLI，M.I.; MARTINEZ， S.C.G.L.; OSTINI, S.; SEGAMARCHI, A.L.; ALMEIDA, G.L. Caracterização da qualidade microbiológica de águas marinhas e moluscos bivalves do litoral norte do Estado de São Paulo. In: CONGRESSO BRASILEIRO DE ENGENHARIA SANITÁRIA E AMBIENTAL, 16, 1991, Goiânia. Anais... Goiânia, 1991. p.430-445.

SECRETARIA ESPECIAL DE AQÜICULTURA E PESCA DA PRESIDÊNCIA DA REPÚBLICA (SEAP/PR), Programa nacional de 
desenvolvimento da maricultura em águas da União. Brasília, 2004.38p.

SILVA, A.I.M.; VIEIRA, R.H.S.F.; MENEZES, F.G.R.; LIMA, L.N.G.C.; NASCIMENTO, S.M.M.; CARVALHO, F.C.T. Bactérias fecais em ostras, Crasssotrea rhizophorae. Arquivo de Ciências do Mar, Fortaleza, v.36, p.63-66, 2003.

SILVA， A.I.M.; VIEIRA， R.H.S.F.; MENEZES, F.G.R.; FONTELES-FILHO, A.; TORRES, R.C.O.; SANTANNA, E.S. Bacteria of fecal origin in mangrove oysters (Crassostrea rhizophorae) in the Coco River estuary, Ceará State, Brazil. Brazilian Journal of Microbiology, São Paulo, v. 35, n.1 e 2, p. 126-130, 2004.

SOUSA, O.V.; VIEIRA, R.H.S.F.; MENEZES, F.G.R.; REIS, C.M.F.; HOFER, E. Detection of Vibrio parahaemolyticus and Vibrio cholerae in oyster, Crassostrea rhizophorae, collected from a natural nursery in the Cocó river estuary, Fortaleza, Ceará, Brazil. Revista do Instituto de Medicina Tropical, São Paulo, v.46, n.2, p.59-62, 2004.

VARNAM, A.H.; EVANS, M.G. Foodborne pathogens: an illustrated text. London: Wolfe Publishing, 1991. p.176-7.
VIEIRA， R.H.S.F.; VASCONCELOS, R.F.; CARVALHO, E.M.R. Quantificação de víbrios, de coliformes totais e termotolerantes em ostra nativa Crassostrea rhizophorae, e na água do estuário do Rio Jaguaribe, Fortim CE. Revista Brasileira de Higiene e Sanidade Animal, Fortaleza, v.1, n.1, p.1-13, 2007. http://dx.doi.org/10.5935/1981-

\subsection{1}

VIEIRA, C. L. Detecção de calicivírus humano (Small Round Structured Virus-SRSV) pela relação em cadeia da polimerase (PCR) em ostras do litoral do Estado de São Paulo. 1999. Dissertação (Mestrado no Instituto de Ciências Biomédicas). Universidade de São Paulo, SP, 1999.

VIEIRA, R.H.S.F.; MENEZES, F.G.R.; REIS, C.M.F.; HOFER, E. Detection of Vibrio parahaemolyticus and Vibrio cholerae in oyster Crassostrea rhizophorae collected from natural nursery in the Cocó River Estuary, Fortaleza, Ceará, Brazil. Revista do Instituto de Medicina Tropical de São Paulo, São Paulo, v. 46, n. 2, p. 59-62, 2004. 
VIEIRA, R.H.S.F.; MORELLI, A.M.F.;

REIS, C.M.F.; RODRIGUES, D.P.; FONTELES FILHO, A.A. Indicadores de contaminação fecal para ostra do mangue (Crassostrea rhizophorae) comercializada na Praia do Futuro, Fortaleza, Ceará. Higiene Alimentar, São Paulo, v.17, n.113, p.81-88, 2003.

WOOD, P.C. Manual de hygiene de los mariscos. Zaragoza: Acribia, 1996, 83p. 
Evangelista-Barreto et al., Revista Brasileira de Higiene e Sanidade Animal (v.2, n.2) p. 18 - 31 (2008) 